\title{
CFD Analysis of The Supersonic Nozzle Flow with Sudden Expansion
}

\author{
Pathan Khizar Ahmed ${ }^{1}$, P. S. Dabeer ${ }^{2}$, S. A. Khan ${ }^{3}$ \\ $\left({ }^{1}\right.$ Research Scholar, Dept. Of Mechanical Engg, Trinity College Of Engineering And Research, Pune, India.) \\ ${ }^{2}$ (Principal, Trinity College Of Engineering And Research, Pune, India.) \\ ${ }_{3}^{3}$ (Department Of Mechanical Engineering, Faculty Of Engineering, IIUM, Malaysia)
}

\begin{abstract}
This paper presents the Computational Fluid Dynamic (CFD) analysis to study the effect of area ratio and nozzle pressure ratio on the flow field of axi-symmetric sudden expansion from convergent-divergent nozzles to a circular duct of larger cross-sectional area than that of nozzle exit area. The study is focusing on the pressure and velocity distribution along axial length. The analysis is done by varying the area ratios and nozzle pressure ratios. The area ratios for the analysis are 1, 2, 4, 6, 8 and 10. The values of nozzle pressure ratios considered are 2, 4, 6, 8 and 10. The results are plotted with the help to graphs. By observing all the results it can be concluded that the flow field in enlarged duct is much affected by area ratio.
\end{abstract}

Keywords: Area Ratio, CFD, Mach number, Nozzle Pressure Ratio, Velocity

\section{Introduction}

The study of base pressure in suddenly expanded flows is a very important field of study and finds applications in many areas. Some of the several applications are the rocket nozzle base Pressure field. The pressure in the base region is generally lower than atmospheric pressure. By considering the above problem it is very important to design the enlarged duct and select proper geometrical parameters. In this paper different cases are analyzed by varying the geometrical and flow parameters so that one can select the best suitable area ratio i.e. the ratio of enlarged duct area to nozzle exit area, for particular nozzle pressure ratio i.e. the ratio of stagnation pressure to back pressure. Flow control is a major rapidly evolving field of fluid dynamics. It implies a small change in the configuration serving large benefits like drag reduction, lift increase, noise reduction etc.

\section{Modeling and meshing}

For modeling and meshing Ansys Workbench 14.5 is used. Cross section of the geometry is shown in the below fig.1.

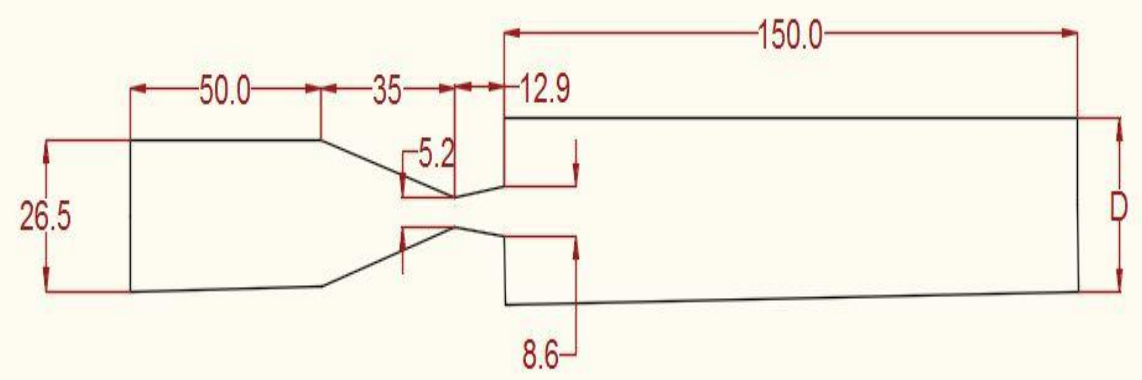

Fig.1: Dimensions of nozzle and enlarged duct

All the dimensions are shown in the above figure are in $\mathrm{mm}$. a pipe of $50 \mathrm{~mm}$ length is added before the nozzle to develop exact inlet flow condition at inlet of the nozzle. The nozzle is designed for Mach number of 2.4. The length of the enlarged duct is considered constant for the cases for better understanding of velocity and pressure distribution along the length. Area ratios for all the cases varies from 1.0 to 10.0 and according to area ratio enlarged duct diameter $(\mathrm{D})$ is calculated.

To get a good quality results the mesh should be structured. The model is divided in number of parts and each part is meshed separately. Completely structured grid is developed as shown in above fig.2. 


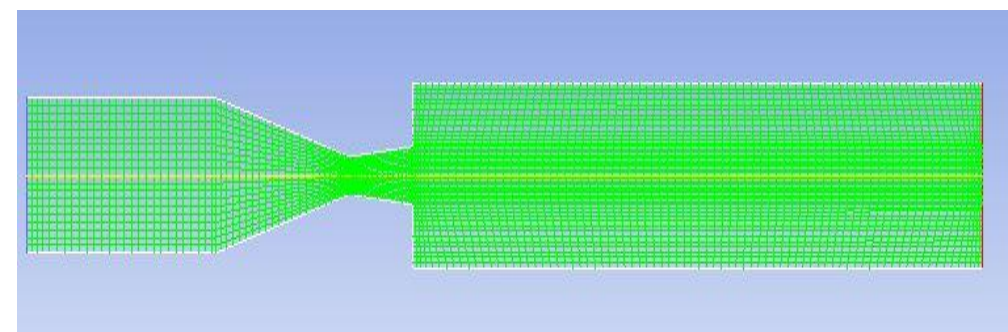

Fig.2: Meshed model of nozzle and enlarged duct

\section{Boundary Conditions}

Zone-type specifications define the physical and operational characteristics of the model at its boundaries and within specific regions of its domain. To analyze all the cases, the boundary conditions defined in Ansys fluent are 'pressure inlet' at inlet and 'pressure outlet' at outlet. The operating pressure is considered as 1 atmospheric pressure. The inlet pressure in all the cases is calculated according to the Nozzle Pressure Ratio NPR. The outlet pressure in all the cases is considered as 1 atmospheric pressure.

\section{Analysis}

The analysis is done by varying the area ratios and nozzle pressure ratios. The values of nozzle pressure ratios considered are 2, 4, 6, 8 and 10 . For each value of nozzle pressure ratio area ratios considered are $1,2,4,6,8$ and 10. The enlarged duct diameter (D) is calculated for each area ratio. The remaining all dimensions are kept constant and shown in fig1. The analysis is done for all possible combinations of flow and geometry parameters and the results are plotted with help of graphs.

\section{Results And Discussion}

By considering the different area ratios and nozzle pressure ratios the analysis is done and $\mathrm{XY}$ plots are generated with the help of postprocessor of Ansys software. The results are generated by considering different area ratios at same nozzle pressure ratios (NPR) and plotted separately. The results for all the cases are shown below.

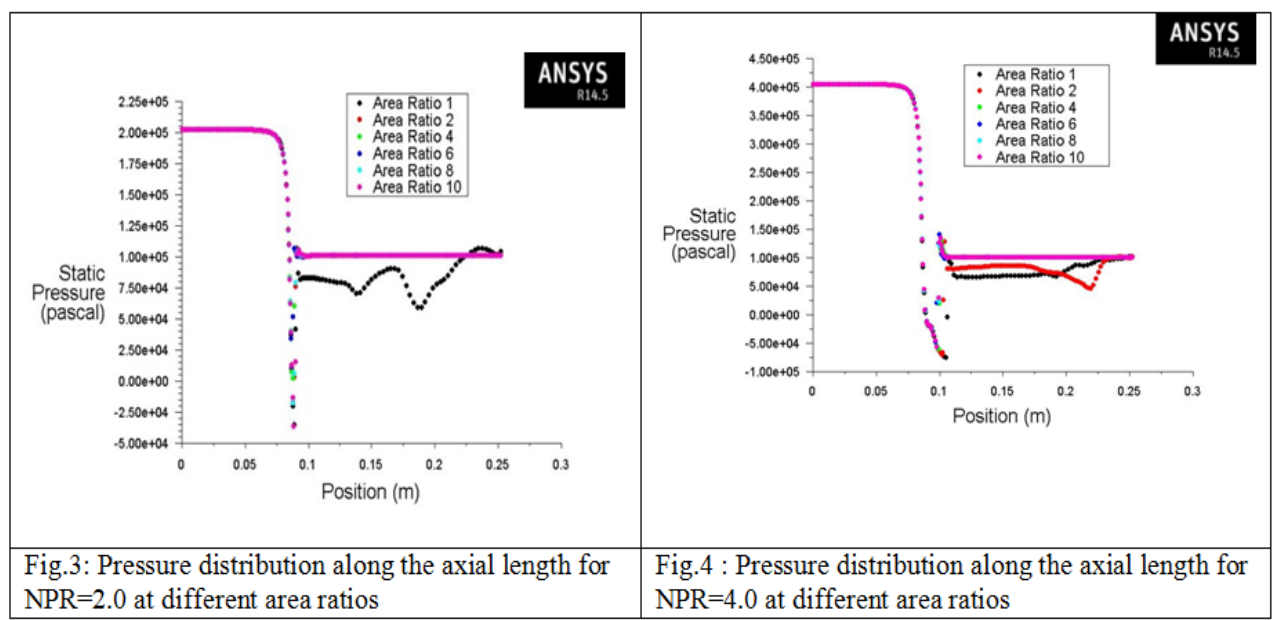

\section{Conclusion}

From the above results it can be concluded that the flow field in enlarged duct is strongly influenced by Nozzle Pressure, area ratio, Mach number and L/D ratio. When the area ratio is low the fluctuations are very high due the non-availability of the relaxation to the flow. When the NPR is very high the flow becomes highly under expanded and the flow field is full of waves, the waves are hitting the wall of the duct and getting reflected, this process continues till the level of under expansion is reduced and the pressure becomes equal to the back pressure. The reattachment length is function of area ratio, it is lowest for smallest area ratio, and increases progressively with increase in the area ratio. When the flow is over expanded for a given Mach number, NPR, area ratio and L/D ratio, after exiting from the nozzle, the jet under goes compression in view of the presence of the oblique shock wave, and this process will continue till it attains the value of the ambient atmospheric pressure. 


\section{References}

[1]. Wicks, R. S., The Effect of Boundary Layer on Sonic Flow Through an Abrupt Cross-sectional Area Change, Journal of the Aeronautical Sciences, Vol. 20, 1953675-682.

[2]. H. Korst, Comments on the effects of boundary layer on sonic flow through an abrupt cross sectional area change, Journal of the Aeronautical Science, Vol. 21, 1954, pp. 568-569.

[3]. R. P. Benedict and N. A. Carlucci, Flow with losses, Trans ASME (Power) Vol. 87, 1965, pp. 37-49.

[4]. Anderson, J. S. and Williams, T. J., "Base Pressure and Noise Produced by the Abrupt Expansion of Air in a Cylindrical Duct”, Journal of Mechanical Engineering Sciences, Vol. 10, No. 3, pp. 262-268, 1968.

[5]. Rathakrishnan, E. and Sreekanth, A. K., "Flow through Pipes with Sudden Enlargement", Proceedings of the 14th International Symposium on Space Technology and Sciences, Tokyo, Japan, pp. 491-499 (1984).

[6]. Kruiswyk, R. W. and Dutton, J. C., "Effect of Base Cavity on Sub-sonic Near-wake Flow", AIAA Journal, Vol. 28, No. 11, pp. 1885-1895, 1990.

[7]. Viswanath, P. R. and Patil, S. R., "Effectiveness of Passive Devices for Axi-symmetric Base Drag Reduction at Mach 2", Journal of Spacecrafts and Rockets, Vol. 27, No. 3, pp. 234-237, 1990.

[8]. Mathur, T. and Dutton, J. C., "Base Bleed Experiments with a Cylindrical After Body in Supersonic Flow", Journal of Spacecrafts and Rockets, Vol., 33, No. 1, pp. 30-37, (1996).

[9]. Khan S. A. and Rathakrishnan E., "Active Control of Suddenly Expanded Flows from Over expanded Nozzles", International Journal of Turbo and Jet Engines (IJT), Vol. 19, No. 1-2, pp. 119-126, 2002.

[10]. Khan S. A. and Rathakrishnan E., "Control of Suddenly Expanded Flows with micro Jets", International Journal of Turbo and Jet Engines (IJT), Vol. 20, No.2, pp. 63-81,2003.

[11]. Khan S. A. and RathakrishnanE," Control of Suddenly Expanded Flow from Correctly Expanded Nozzles”, International Journal of Turbo and Jet Engines (IJT), Vol. 21, No. 4, pp. 255-278 (2004).

[12]. Khan S. A. and Rathakrishnan E., "Nozzle Expansion Level Effect on a Suddenly Expanded Flow", International Journal of Turbo and Jet Engines(IJT), Vol. 23, No. 4, pp. 233-258, 2006.

[13]. Maughal Ahmed Ali Baig, S. A. Khan and E. Rathakrishnan, "Active Control Of Base Pressure In Suddenly Expanded Flow For Area Ratio 4.84", International Journal of Engineering Science and Technology (IJEST), Vol. 4, No. 5, pp 1892- 1902, May 2012.

[14]. Maughal Ahmed Ali Baig, S. A. Khan and E. Rathakrishnan, "Base Pressure Studies from Over Expanded Nozzle for Area Ratio 2.56", International Journal of Current Research and Review (IJCRR), Vol. 4, No.11, June 2012, pp 107-113.

[15]. Syed Ashfaq, S. A. Khan and E. Rathakrishnan, Active Control of Flow through the Nozzles at Sonic Mach Number, International Journal of Emerging Trends in Engineering and Development, Vol. 2, Issue-3, 2013, pp. 73-82.

[16]. Syed Ashfaq, S. A. Khan and E. Rathakrishnan, Control of suddenly expanded flow for area ratio 3.61, International Journal of Advanced Scientific and Technical Research, Issue 3 volume 6, Nov.-Dec. 2013, pp. 798-807.

[17]. Maughal Ahmed Ali Baig, S. A. Khan Ahmed Saleel C and E. Rathakrishnan "Control Of Base Flows With Micro Jet For Area Ratio Of 6.25”, ARPN Journal of Engineering and Applied Science, Vol.7, No.8, pp 992-1002 August 2012.

[18]. Maughal Ahmed Ali Baig, F. Al-Mufadi, S. A. Khan and E. Rathakrishnan, "Control of Base Flows with Microjets", International Journal of Turbo Jet Engines, Vol. 28 (2011), pp. 59-69

[19]. Syed Ashfaq and S. A. Khan, Experimental Studies on Low Speed Converging Nozzle Flow with Sudden Expansion, International Journal of Emerging Technology and Advanced Engineering, Volume 4, Issue 1, January 2014, pp. 532-540.

[20]. Syed Ashfaq and S. A. Khan, Studies on Flow from Convergent Nozzle with Sudden Expansion and Control Effectiveness under the Influence of Micro Jets, International Journal of Research in Mechanical Engineering \& Technology, Volume 4, Issue 1, April 2014,ISSN : 2249-5762 (Online) | ISSN : 2249-5770 (Print) pp. 76-87, 2014. 